\title{
Hydrodynamic modelling of floodplain flow residence time in a wet tropical catchment, north eastern Australia
}

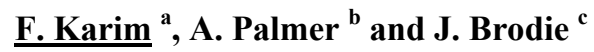 \\ ${ }^{a}$ CSIRO Land and Water, Black Mountain Laboratories, Canberra, Australia \\ ${ }^{b}$ CSIRO Land and Water, Ecoscience Precinct, Brisbane, Australia \\ ${ }^{c}$ Centre for Tropical Water \& Aquatic Ecosystem Research, JCU, Townsville, Australia \\ Email: fazlul.karimt@,csiro.au
}

\begin{abstract}
Vegetated systems (e.g. grassed strips, riparian vegetation, wetlands, sumps) are increasingly being incorporated into farming systems in north Queensland, especially in the catchments draining to the Great Barrier Reef (GBR) lagoon, to improve downstream water quality. The residence time of water in trapping mediums is an important measure of likely effectiveness of any vegetated area. While residence time of catchment runoff in the GBR lagoon before it is transported to the open ocean is reported in many studies, quantitative estimates of water residence time in the river-floodplain system for majority of the GBR catchments is generally unknown. This study focused on the Tully-Murray catchment in the wet tropics which is frequently flooded ( 2 to 3 floods in each year) and carries a large quantity of land sourced contaminants to the GBR lagoon during overbank flow events. A two-dimensional floodplain hydrodynamic model (MIKE 21) was used to simulate spatial and temporal variations of velocities across the floodplain. This information was used to estimate mean residence time on the floodplain before flood water from agricultural lands reaches coastal waters. The model was calibrated using measured inundation depths and velocities at 53 locations on the floodplain for a recent flood in 2013, which was about 2.3 times bigger than a mean annual flood. A range of water residence times has been extracted for in-channel and floodplain waters for different floods. This information is useful to estimate denitrification, pesticide degradation and sedimentation by combining residence time with pollutant decay rules to assess the effectiveness of vegetated areas.
\end{abstract}

Keywords: Floodplain, residence time, vegetated system, water quality, GBR 


\section{INTRODUCTION}

Excess terrestrial loads of sediment, nutrients and pesticides derived from agriculture have been recognised as the major cause of water quality degradation in estuaries and marine waters of the Great Barrier Reef (GBR) lagoon (Brodie et al. 2012a). Since European settlement the discharge of pollutants to the GBR lagoon has greatly increased; the sediment yield has risen by an estimated factor of 5.5, while total nitrogen and phosphorus loads have increased by factors of about 6 and 9, respectively (Kroon et al., 2012). Deterioration of water quality reaching the GBR lagoon and subsequent degradation of marine habitats continues to be attributed to land use modifications and land management practices in GBR catchments (Brodie et al., 2012a). In order to protect the GBR, efforts to mitigate and prevent any further degradation are increasing. Introducing a vegetated patch adjacent to farming lands or revegetating floodplains and wetlands could be an option to reduce agricultural loads to GBR. However, only limited research has been conducted into the ability and efficiency of vegetated systems to trap pollutants. It is well documented that the degree of pollutant removal greatly depends on flow residence time (e.g. Wang et al., 2007; Brodie et al., 2012b). An important issue is to estimate the flow velocity on the floodplain, which greatly differs from in-channel flow (Helton et al., 2012).

The bulk of land derived pollutants to the GBR lagoon are delivered by river floods (Wallace et al. 2009) and much of the rivers' freshwater discharge occurs in short-lived flow events, with on average 2 to 3 floods per year for rivers in the wet tropics and 1 flood per year for the dry tropical rivers (Furnas, 2003). The residence times of these flow events varies between catchments in the range of few days for a small river catchment (e.g. Ross River, Tully River) to a few weeks and up to a few months for the two largest GBR catchments, the Burdekin and Fitzroy (Brodie et al., 2012b). While there have been a number of previous studies to estimate residence times of water in the GBR lagoon (e.g. Luick et al., 2007; Wang et al., 2007; Choukroun et al., 2010) using hydrodynamic modelling and remote sensing technologies, studies on estimating residece time on the floodplain environment are still limited. A few studies estimated the river flood times for the selected catchments of GBR lagoon (e.g. Lambrechts et al., 2010; Webster and Ford, 2010). The residence time in the floodplain however differs greatly from the mean flood speed due to the complex nature of floodplain flow (Helton et al., 2012). In this study we have investigated water residence time in the TullyMurray catchment which is a relatively small catchment but discharges large quantities of contaminants to the GBR lagoon during floods.

\section{STUDY AREA AND DATA}

\subsection{Location and hydrology}

The Tully-Murray catchment is located in the Wet Tropics region of the north-east coast of Australia (Figure 1) and is one of the many catchments that drain into the GBR Lagoon. It covers an area of $2072 \mathrm{~km}^{2}$, of which $832 \mathrm{~km}^{2}$ is floodplain (Karim et al., 2008). Topography varies from steep rainforest-covered mountains in the upper catchment to low-relief floodplains which are largely developed for agriculture (mainly sugarcane and bananas) and grazing.

The Tully and Murray Rivers are the two main waterways on the floodplain (130 and $70 \mathrm{~km}$ long, respectively) and receive catchment runoff through numerous tributaries. The length of floodplain varies from $38 \mathrm{~km}$ along the Tully River and 42 $\mathrm{km}$ along the Murray River. The Tully River has well developed natural levee banks which have been

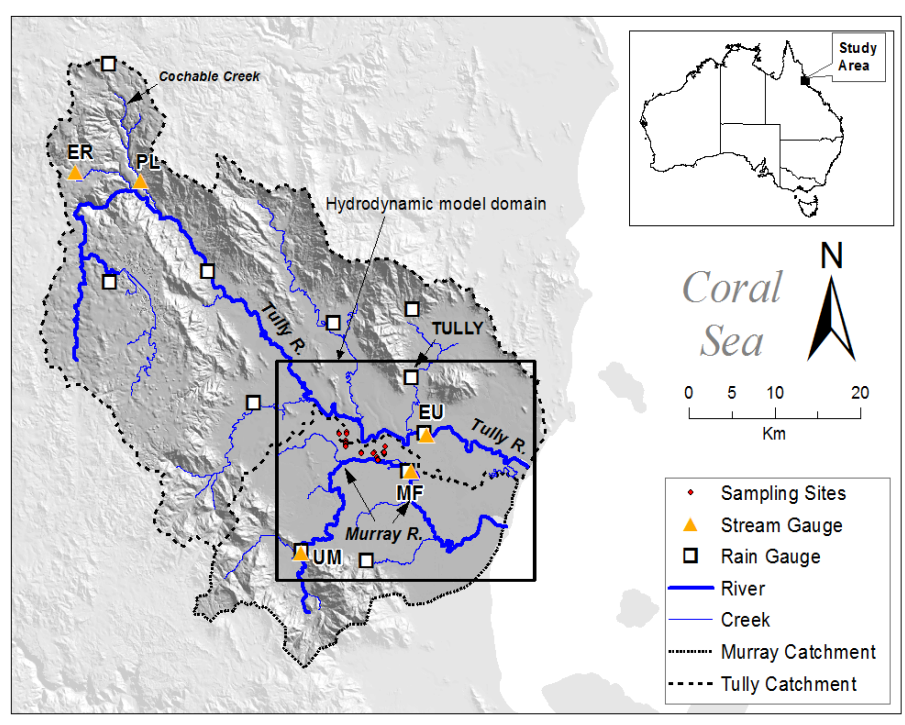

Figure 1 Study area map showing the Tully and Murray catchments and major streams. The rectangle shows the hydrodynamic modelling domain $(30 \times 24 \mathrm{~km})$. The location of stream gauges in the upper catchment (ER, Ebony Road, PL, Power line) and in the floodplain (UM, Upper Murray; MF, Murray Flats; ER, Euramo) is shown. The red dots are the sampling sites where water depth and velocity were measured. 
extended artificially in places. The general slope of the floodplain between the Tully and Murray rivers is from the elevated levees adjacent to the Tully to lower elevations adjacent to the Murray. This slope results in the flow of floodwater from the Tully into the Murray during overbank floods. The catchment receives a mean annual rainfall of between 2000 and $4000 \mathrm{~mm}$ depending on location, with most rainfall $(60-80 \%)$ occurring during the wet season between December and April. During this period floodplains are inundated by an average of 3 to 4 floods per year (Wallace et al., 2009). The mean annual flood has a discharge about twice the bank-full discharge. Because the topography of the Tully-Murray floodplain is very flat and the rivers are quite close, water from the two rivers often merges during a flood.

\subsection{Stream flow}

Gauged data were used to specify model boundaries and to calibrate the rainfall-runoff and hydrodynamic models. Mean daily discharge and stage height data were obtained from the Queensland Department of Environment and Resource Management (DERM) for the period of 1972-2013. The Tully River has two gauges in the upper catchment and one gauge on the floodplain, while the Murray River has one gauge in the upper catchment and one on the floodplain (Figure 1). Gauged data in the upper catchment were used to estimate inflow at the hydrodynamic model boundaries and floodplain stage-height records were used to calibrate the model. Flows recorded in the lower Tully (at Euramo) were used to test the hydrodynamic model predictions of flood speed and peak arrival at Euramo. We also conducted field sampling between 2628 January 2013 to measure the inundation depth and velocity across the floodplain when flood waters were receding from the sugarcane fields. These data were used to test the hydrodynamic model predictions of water depth and velocity at different locations. A total of 53 sites were visited in the floodplain between the Tully and Murray Rivers (locations are shown on Figure 1). In most places we accessed the site by a 4WD car and in some places where water depth was high we accessed the site by a small boat. At each location we took 3 to 5 readings and data were processed to calculate mean velocity at that point. We used a simple handheld velocity measuring device (FlowTracker Handheld-ADV, SonTek) to track flow direction and magnitude. Coordinates and time of measurement were recorded using the Garmin GPS 72H.

\subsection{Topography and surface roughness}

The topography of the study area used in the hydrodynamic model was a $30 \mathrm{~m}$ grid digital elevation model (DEM). This DEM was primarily based on one coarse resolution $( \pm 0.7)$ areal photogrammetry data for the entire floodplain area and one fine resolution $( \pm 0.15 \mathrm{~m}$ vertical accuracy) data set along the main highway and railway. The bathymetry of the Tully and Murray Rivers and major creeks was added to the DEM using surveyed cross-sections. As creek widths are relatively small (10 to $70 \mathrm{~m})$ and at many locations less than the model grid size, the creek width was adjusted to ensure a continuous creek section until it met with a river or another creek. Fine scale details for the main wetlands in the floodplain were embedded into the $30 \mathrm{~m}$ DEM using re-sampled $3 \mathrm{~m}$ LiDAR data. Bathymetry of the wetlands was estimated using a combination of LiDAR data (i.e. above their end of dry season water level) and field surveys of the submerged bathymetry. Wetlands were reproduced in the model using a set of rectangular grids ensuring the surface area was kept as close as possible to the actual wetland area.

We used Manning's roughness coefficients $n$ to represent land surface resistance to the propagating flood wave. A surface roughness map was developed for the hydrodynamic domain with the same size grid as the hydrodynamic model using the Queensland land use map (Pitt et al., 2007). Initial roughness coefficients were estimated based on land use and then refined as a part of the model calibration process. Land use in the Tully-Murray floodplain is dominated by sugarcane plantations, interspersed with some grazing land. The next largest land use is banana farming, which is concentrated in the upstream reaches of the Tully floodplain. To produce a hydraulic roughness map, vegetation cover was classified as sugar cane, banana, grazing, cereal and urban. The water bodies were categorised as wetlands, creeks, and rivers. Sugarcane roughness is very dependent on the cane growth stage at the time of flooding (i.e. a fallow field can create a flow path while a fully mature cane field can act as a strong impediment to flow). River flow records show that most of the overbank events occur between January and March (Wallace et al., 2009), when cane fields are generally fully covered by plants, so a high roughness value was adopted for cane areas.

\section{HYDRODYNAMIC MODELLING}

\subsection{Model configuration}

The hydrodynamic model was configured for the combined Tully and Murray floodplains including estuaries at the downstream end. The computational domain was $720 \mathrm{~km}^{2}(30 \times 24 \mathrm{~km})$ covering the entire floodplain 
(Figure 1), which is $32 \%$ of the total catchment area. Inputs to the model were land elevation, surface roughness and water sources. Model boundaries include inflows through the Tully and Murray Rivers, and through 4 creeks. At the downstream, seaward boundary water levels equal to the Mean High Water Spring (MHWS) tide were used. The downstream boundaries were set sufficiently distant from the floodplain so that boundary effects (if any) were insignificant on floodplain flows. The inflows at the intersection of streams and hydrodynamic model boundaries were estimated using a calibrated rainfall-runoff model. The detail of rainfall-runoff modelling can be found in Karim et al. (2012). The upstream boundaries were set well above the floodplain to capture and define the upper catchment flows onto the floodplain.

We used a two-dimensional floodplain hydrodynamic model (MIKE 21; DHI, 2008) to simulate flood wave propagation and to estimate flow velocity across the floodplain. The MIKE 21 model is fully dynamic and is based on the depth-averaged Saint-Venant equations to describe the evolution of water levels, and two Cartesian velocity components. The model produces grid-based water level and velocity components in two horizontal axes (the $x$ and $y$ ) over the entire computational period.

\subsection{Simulations}

Water sources on the floodplain include locally generated runoff and inflows from the upper catchments. We estimated local runoff as well inflows through the stream using the previously calibrated NAM rainfall-runoff model (Karim et al., 2012). The Tully and Murray catchments were divided into a number of sub-catchments based on land topography. Sub-catchment boundaries and stream networks were generated using ArcGIS Hydro Tools. The area above the hydrodynamic model domain was divided into 15 sub-catchments with an average area of $96 \mathrm{~km}^{2}$, based on stream networks that carry upper catchment runoff to the floodplain. Runoff for individual sub-catchments was estimated separately and then propagated through sub-catchments further downstream. Runoff within the hydrodynamic domain was simulated using much smaller subcatchments with an average area of $9.7 \mathrm{~km}^{2}$. Sub-catchment boundaries and location of their outlets were obtained from previous hydrodynamic modelling studies of Karim et al. (2012). A total of 66 subcatchments, 19 linked with the Tully River and 47 linked with the Murray River, were used in the floodplain. Modelled runoff was added to the hydrodynamic model as a point source at the outlet of each sub-catchment.

The hydrodynamic model domain was divided into 800,000 computational grids each $30 \mathrm{~m}$ by $30 \mathrm{~m}$. The computational time increment was derived after satisfying numerical stability criteria. A time step of 4 sec was used as this produced a stable solution for floods with a return period of up to 50 year. Simulation of each flood event was carried out for 12 days to include the full flooding period of the largest flood. Computed time-varying water depth and velocity were recorded hourly at some selected points and twohourly for all computational points. Spatial variation of flow velocity across the floodplain was extracted using MIKE 21 toolbox.

\subsection{Calibration}

The hydrodynamic model was calibrated for a recent flood in 2013 (22-28 January) which was about 2.3 times bigger than a mean annual flood by comparing observed and simulated stage heights and velocities. During the calibration process, floodplain topography was slightly modified at some locations to rectify model instability due to high velocities that occurred at sharp gradients. Surface roughness coefficients (Manning's $n$ ) were varied iteratively for the major land uses (sugarcane, banana and grazing) within the recommended range to attain close agreement between measured and simulated water heights in the river and on the floodplain. The calibrated $n$ value for sugarcane is 0.20 which is the maximum among the land uses followed by urban area $(n=0.12)$, banana $(n=0.10)$ and grazing $(n=0.09)$.

\subsection{Sensitivity of flood magnitude}

Flood scenarios were estimated for 3 storm events for the ARI (average recurrence interval) of 1, 20 and 50 years. Design rainfalls for these storm events were estimated using rainfall frequency analyses for the Tully area. These estimates were based on the CRC-FORGE method (Durrant and Bowman, 2004). Predicted annual rainfall for 1, 20 and 50 ARI storm events were 408, 672 and $813 \mathrm{~mm}$ respectively. Temporal distributions of rainfall for the above events were obtained using 4-hourly temporal pattern hyetographs (Pilgrim et al., 2001). The critical storm duration for floods in the Tully-Murray floodplain is 72 hours. Combining this with temporal patterns hyetographs gave rainfall distributions for 72-hour storms that were divided into 18 periods each of 4 hours duration. Runoff values were then simulated using the previously calibrated NAM runoff model (Karim et al., 2012). 


\section{RESULTS AND DISCUSSION}

\subsection{Flow velocity}

As part of model calibration a comparison between simulated and observed stage heights at the main catchment outlet (Euramo on the Tully River) was performed to ensure that model simulated speed of flood wave propagation that is representative of observed flood speed. Agreement between simulated and observed stage heights was reasonably good and the differences at any time were less than $\pm 7 \%$. The difference between simulated and observed peaks was less than $3 \%$.

Figure 2 shows a comparison of simulated velocity at 53 locations where velocities were measured during the 2013 flood. Velocities between locations on floodplain vary in the range of 0 to $0.6 \mathrm{~m} / \mathrm{s}$. This is due to land slope and surface resistance. For example flow velocity at the entry point of sugarcane field is much higher than the velocity of flow leaving the sugarcane primarily due to resistance to flow by sugarcane. At 4 locations simulated velocities were found to be zero. Though there are large differences in point to point comparison overall the coefficient of determination is reasonable $\left(r^{2}=0.76\right)$. Discrepancies are large for the low velocities while for large velocities simulated velocities are very close to observed velocity. Difficulties in measuring low flow in the field have contributed to the difference between simulated and observed velocity.

We investigated how flow velocity changes within in floodplain environment with respect to channelized flow. This gave us an indication of residence time in the floodplain. Figure 3 shows the simulated mean velocity at different locations along the Tully River starting from the upstream end of the hydrodynamic model boundary. It also shows discharge hydrographs at 2 locations (one at the upstream boundary and other at $15 \mathrm{~km}$ downstream). While discharge varies very little between locations, mean velocity can be greatly different based on location along the stream. At the upstream boundary flow is confined within the river bank, therefore velocity increases with increasing discharge (or stage height). The velocity curve at $5 \mathrm{~km}$ downstream indicates flow

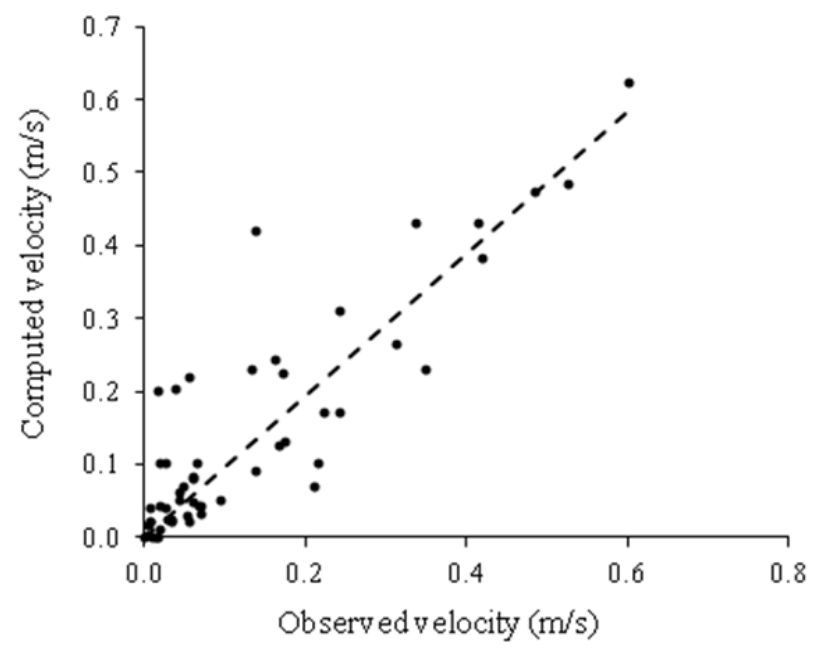

Figure 2 Comparison of measured versus simulated flow velocity on the floodplain between Tully and Murray Rivers. The dashed line (---) is the fitted linear regression line $\left(V_{\text {sim }}=0.97 V_{o b s}\right.$ with $\left.r^{2}=0.76\right)$.

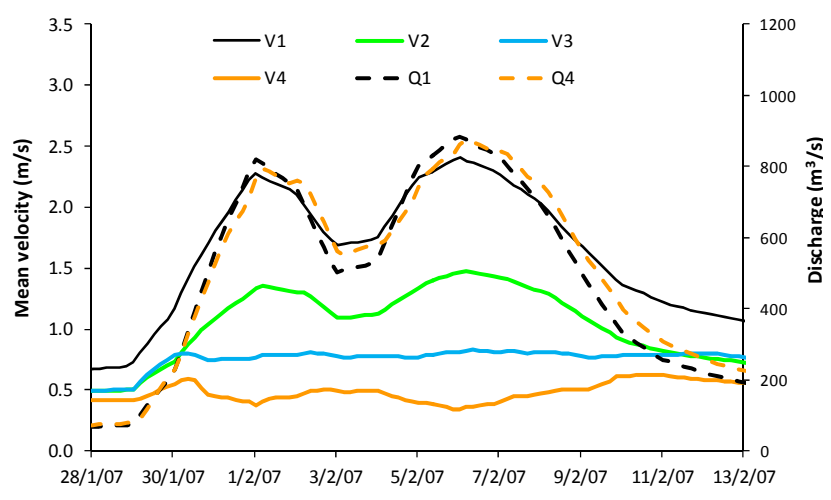

Figure 3 Spatial and temporal variation of flow velocity along the Tully River for the flood event in 2007 (V1, V2, $\mathrm{V} 3$ and V4 are mean velocity at $0,5,10$ and $15 \mathrm{~km}$ downstream respectively from upstream boundary of the model, Q1 and Q4 are discharge at 0 and $15 \mathrm{~km}$ downstream respectively). is still within riverbanks but river sections are greatly enlarged. The velocity curves at 10 and $15 \mathrm{~km}$ downstream indicate overbank flow conditions where velocity first increases with increasing discharge and then decreases due to spreading of flow overbank. The reason is that when it starts overflowing cross sectional area increases therefore mean velocity decreases. It can be seen that velocity at the lower end of the floodplain can be as small as $1 / 4$ of the upstream velocity. This indicates water residence time on the floodplain is much higher than it is for channelized flow. 
Figure 4 shows an example of relative magnitude of floodplain flow velocities with respect to in-stream flow at a midsection on the floodplain. Apart from mean velocity, grid based velocity is smaller on the floodplain and it varies greatly between locations. It is noticed that the difference between floodplain velocities are more pronounced when instream velocity is relatively low. This is a situation when inundation depth is small and flood wave propagation is influenced more by surface resistance. Result shows velocities are high for locations close to river (e.g. FP1, FP2). With distance from the river velocity decreases due to surface resistance and it produces very small or zero velocity for a distant location (e.g. FP5). However this pattern could be different if topography and/or land use differs greatly.

\subsection{Water residence time}

The residence time for in-stream flow in the Tully catchment is less than a day from the upstream end of the floodplain before flood water reaches to GBR lagoon. The length of the Tully River for its floodplain part is approximately 38 $\mathrm{km}$ and if we assume a grid velocity of $1.3 \mathrm{~m} / \mathrm{s}$ as wave celerity then flood water takes about 8 hours to reach the coast. If we consider mean velocity of $0.5 \mathrm{~m} / \mathrm{s}$ then residence time is approximately 1 day. Residence time on the floodplain differs greatly between locations. However it is still within couple of days as water finds its way into cane drains and allows it to move faster. Figure 5 shows an example of inundation duration across the floodplain for a flood event of 1-year ARI. While much of floodplain shows less than 6 days of inundation for a 3 day storm event, some areas in the vicinity of the Murray River shows about 12 days of inundation. These are the places where residence time could be several days. Flat land slope is one of the reasons for this inundation behaviour. Large floods (e.g. ARI 20 and 50 years) produced longer duration of inundation but actual residence time on the floodplain is less due to high flow velocity for a large flood event. In this study we used $30 \mathrm{~m}$ DEM to represent land topography and thus couldn't reproduce levee banks along the river adequately. A finer resolution DEM (e.g. $5 \mathrm{~m}$ ) could be useful to improve estimates of flow exchange between river and floodplain and thus residence time on the floodplain.

\section{CONCLUSIONS}

In this study we have calibrated a two-dimensional floodplain hydrodynamic model to estimate water residence time on the floodplain. During a flood event, estimated residence time for in-bank flow is less than a day while it can be several days on the floodplain based on location. Land slope and land cover with high resistance to flow (e.g. sugar cane) are the major factors contributed to residence time. If time permits further validation of the model will be performed for a separate flood. We will use the calibrated model to estimate changes in residence time for different flow events and land uses. This information will be combined with 
Karim et al., Hydrodynamic modelling of floodplain flow residence time in a wet-tropical catchment

decay rules to assess effectiveness of different vegetated system to remove pollutant from flood water before it reaches to a stream.

\section{ACKNOWLEDGMENTS}

This research was funded by the Queensland Government Department of Environment and Heritage Protection. We acknowledge the supply of stream flow data from the DERM of Queensland Government and rainfall data from the BOM. The authors acknowledge Brett Baker and Joseph Kemei for their assistance with field work.

\section{REFERENCES}

Brodie, J.E., F.J. Kroon, B. Schaffelke, E.C. Wolanski, S.E. Lewis, M.J. Devlin, I.C. Bohnet, Z.T. Bainbridge, J. Waterhousea, and A.M. Davis (2012a). Terrestrial pollutant runoff to the Great Barrier Reef: An update of issues, priorities and management responses. Marine Pollution Bulletin, 65, 81-100.

Brodie, J.E., E.C. Wolanski, S.E. Lewis, Z.T. Bainbridge (2012b). An assessment of residence times of land-sourced contaminants in the Great Barrier Reef lagoon and the implications for management and reef recovery. Marine Pollution Bulletin, 65, 267-279.

Choukroun, S., P.V. Ridd, R. Brinkman, and L.I.W. McKinna (2010). On the surface circulation in the western Coral Sea and residence times in the Great Barrier Reef. J. Geophys. Res. 115, C06013

DHI, 2008. MIKE 21 Flow Model: Scientific Documentation, DHI: Denmark; 60.

Durrant, J.M. and S.Bowman (2004). Estimation of Rare Design Rainfalls for Western Australia: Application of the CRC-FORGE Method. Surface Water Hydrology Report No. HY17, Department of Environment, Government of Western Australia; 120

Furnas, M.J. (2003). Catchments and Corals: Terrestrial Runoff to the Great Barrier Reef. Australian Institute of Marine Science and CRC Reef, Townsville, Australia, 334p.

Helton, A.M., G.C. Poole, R.A. Payn, C. Izurieta, and J.A. Stanford (2012). Relative influences of the river channel, floodplain surface, and alluvial aquifer on simulated hydrologic residence time in a montane river floodplain. Geomorphology (in press).

Karim, F., A . Kinsey-Henderson, J.S. Wallace, P. Rash, A.H. Arthington, and R.G. Pearson (2008). An assessment of wetland connectivity in the Tully-Murray floodplain using a hydrodynamic model. In Proceedings of the 2008 Marine and Tropical Sciences Research Facility Annual Conference. Taylor R and Long S (eds). Reef and Rainforest Research Centre Ltd: Cairns; 64-70.

Karim F., A. Kinsey-Henderson, J. Wallace, A.H. Arthington, and R.G. Pearson (2012). Modelling wetland connectivity during overbank flooding in a tropical floodplain in north Queensland, Australia. Hydrological Processes 26: 27102723.

Kroon, F.J., P.M. Kuhnert, B.L. Henderson, S.N. Wilkinson, A.K. Henderson, B. Abbott, J.E. Brodie, R.D.R. Turner (2012). River loads of suspended solids, nitrogen, phosphorus and herbicides delivered to the Great Barrier Reef lagoon. Marine Pollution Bulletin, 2012. 65(4-9), 167-181.

Lambrechts, J., C. Humphrey, L. McKinna, O. Gourge, K. Fabricius, A. Mehta, S. Lewis, and E. Wolanski (2010). The importance of wave-induced bed fluidisation in the fine sediment budget of Cleveland Bay, Great Barrier Reef. Estuar. Coast. Shelf Sci. 89, 154-162.

Luick, J.L., L. Mason, T. Hardy, and M.J. Furnas (2007). Circulation in the Great Barrier Reef Lagoon using numerical tracers and in situ data. Cont. Shelf Res. 27, 757-778.

Pilgrim, D.H., M.R. Kennedy, I.A. Rowbottom, I. Cordery, R.P. Canterford and L.H. Turner (2001). Temporal patterns of rainfall bursts. Australian Rainfall and Runoff: A Guide to flood Estimation. Volume 1, Book II, Institution of Engineers Australia: Canberra (in CD ROM).

Pitt G., S. Grounds, D. van den Berg, and R. Denham (2007). Mapping Land Use - Land Use Change Mapping from 1999 to 2004 for the Tully River Catchment, Department of Environment and Resource Management; Brisbane: 21p.

Wallace, J., L. Stewart, A. Hawdon, R. Keen, F. Karim, and J. Kemei (2009). Flood water quality and marine sediment and nutrient loads from the Tully and Murray catchments in north Queensland, Australia. Marine and Freshwater Research 60: 1123-1131.

Wang, Y., P.V. Ridd, M.L. Heron, T.C. Stieglitz, and A.R. Orpin (2007). Flushing time of solutes and pollutants in the central Great Barrier Reef lagoon, Australia. Marine Freshwater Research 58, 778-791.

Webster, I.T., and P.W. Ford (2010). Delivery, deposition and redistribution of fine sediments within macrotidal Fitzroy Estuary/Keppel Bay: Southern Great Barrier Reef, Australia. Cont. Shelf Res. 30, 793-805. 